\title{
Effective Conduction of University Safety Education in Scientific Practices through an Integrated Manner
}

\author{
Miao $\mathrm{Yu}^{1}$, Tao Zhou ${ }^{1, *}$, Chen Dong ${ }^{1}$, Yang $\mathrm{Xie}^{1}$, Zhitao $\mathrm{Hu}^{1}$ and Deng-Guang $\mathrm{Yu}^{1}$ \\ ${ }^{I}$ School of Materials Science \& Engineering, University of Shanghai for Science \& Technology, Shanghai 200093, \\ China. \\ *Corresponding author. Email: zhoutao310@163.com
}

\begin{abstract}
For high quality high education, safety education is one of the most important sections, particularly the scientific practice safety education to those students majoring in the natural disciplines. In this paper, an integrated method is put forward for effective conduction of university safety education in scientific practices to graduate and undergraduate students, which is through a combination of classroom lessons, experiments, and final examination. During the safety education process, the spirit of "three-whole education" is explored as a guide, particularly the whole-process education. The professional course "Advanced methods for materials characterization" was utilized as an example to conduct the "whole-process" safety education, from classroom to laboratory experiments, and to the final examination. After finishing the safety education, it is obvious that all the students not only well grasp the theoretical knowledge about safety education, but also are trained to do experiments in a safe manner. What is more, the integrated manner has significantly improved the students' safety awareness.
\end{abstract}

Keywords: safety education; classroom lesson; experiments; examination; undergraduate students;

postgraduate students

\section{INTRODUCTION}

Safety education of all kinds of students (including undergraduate and postgraduate) is one of the important contents that should be conducted to improve higher education quality and train qualified talents. Particularly, many students lack of fundamental safety knowledge and have weak self-protection awareness during their study, life, growth, and also professional lessons. Among types of safety education, the safety education associated with the students' scientific practices in one of the urgent and important one for their growth into professional talents. Effective safety education associated with the students' scientific practices should strengthen the self-cultivation capability of college students, keep their healthy psychology, form good safety habits during practices, and help them improve safety awareness, master fundamental safety knowledge and harm-prevented skills, and enhance self-defense ability.

Meanwhile, safety education should not be taught to the students in a separate manner or in a temporary emergency mode. It is better to carry out during all the lesson processes and be melt into the study life, particularly the scientific practice processes. These processes include the professional courses in the classroom, their course experiments, their innovation projects, the scientific practices, and even their final examinations.

In this paper, we investigate a combined model. The mode can be exploited for systematic implement of safety education in scientific practices on graduate and undergraduate students through a systematic combination of classroom lessons, experiments, and final examination (Figure 1). For illustration purposes, a professional course "Advanced methods for materials characterization", a course given to the senior undergraduate students and also the postgraduate students for Master and doctoral degree, is explored as an example.

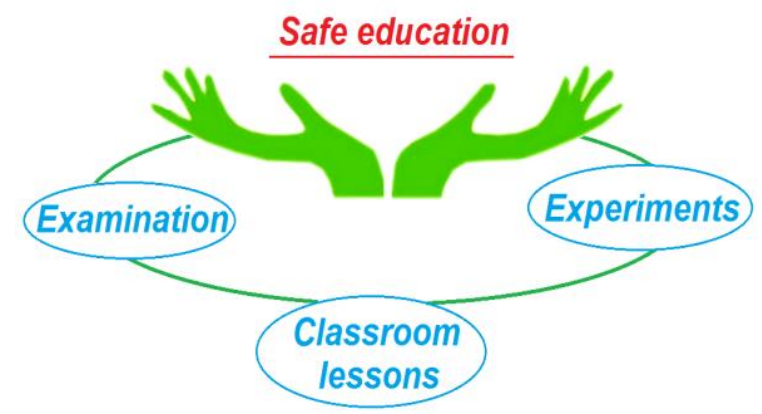

Figure 1. To Implement safe education on graduate and undergraduate students through a systematic combination of classroom lessons, experiments, and final examination. 


\section{CLASSROOM LESSONS ON SAFETY EDUCATION}

The concept of "three-whole education" for comprehensive reform of high education is spread to all the universities in China in 2018 by the Ministry of Education. According to the spirit, "three-whole education", including whole-staff education, whole-process education and whole-round education, has given a light on how to carry out the scientific practices safety education in university. Needless to say, all the professional courses can comprise one of the sections of the "whole-process" safety education.

"Advanced methods for materials characterization" is an important professional basic course for all students majoring materials disciplines. This course focuses on the working principle of common modern analytical and testing instruments and their application in material characterization and analysis. The main contents focus on some dimensional nano material morphology and structure analysis instruments (such as optical microscope, scanning electron microscope, transmission electron microscope, atomic force microscope), material composition analysis instruments for component state and interaction between composite components (such as energy spectrometer, infrared spectrometer, Raman spectrometer, X-ray crystal diffraction), analysis instruments for basic thermal and electrical properties of materials (such as thermogravimetric analyzer, differential scanning calorimetry analyzer and electrical energy detector), and preliminary quantitative analysis instruments (such as ultraviolet visible spectrophotometer energy spectrometer). After the study of the courses, the students will not only have the abilities of grasping professional skills for conducting the characterizations on advanced functional materials, but also the capability of obtaining effective data and atlas from various analytical instruments, of correctly analyzing these data and atlas, and providing solutions for complex material engineering problems, and the abilities of safety awareness, expression ability, team spirit and ability to play a role in the team in project implementation.

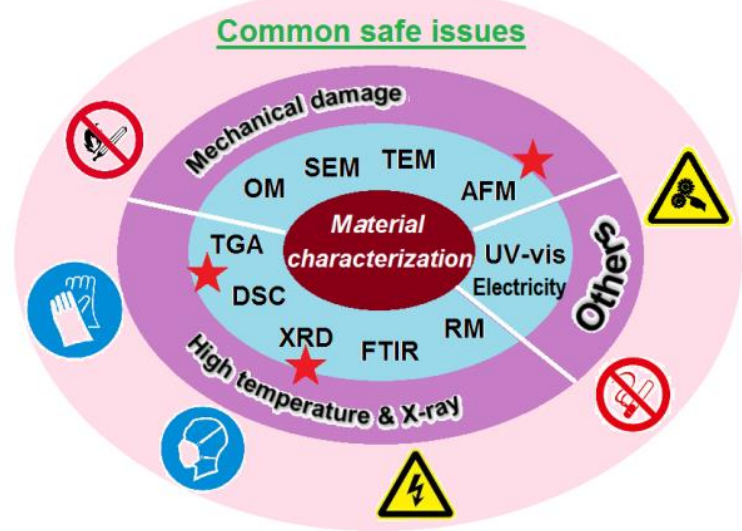

Figure 2. The analysis methods taught in the classroom and their key elements in safety education.
As an important section of the "whole-process", classroom safety education should be carefully organized by the teachers and the important contents should be summarized and categorized. A diagram is shown in Figure 2, in which the main issues associated with the possible harms are concluded. These issues are mainly common issues that not only occur in the scientific laboratories, but also in numerous industrial productions, and thus is very important for the students' growth.

For the effective safety education, there are three levels on all the characterization methods. The first level is that the students should know clearly the possible safe issues associated with each instrument. These issues include high temperature and high energy (X-ray) from the instruments such as such as thermogravimetric analyzer (TGA), differential scanning calorimetry analyzer (DSC), and Xray diffraction (XRD); possible mechanical damages during the sample preparation processes such as optical microscope (OM), scanning electron microscope (SEM), transmission electron microscope (TEM), and atomic force microscope (AFM); and other safety issues such as ultraviolet damage from the UV-vis spectrophotometer and possible electric shock from the conductivity measurement. The second level is that the students should know how to prevent the possible safe issues and effectively protect themselves. For this purpose, they should not only obey the rules of each laboratories, but also good self-safety awareness and quality; they should know conventional safety protection methods and safety problem handling steps and methods. The third level is that they can take charge of safety, not only their owns, but also other persons and the whole laboratories.

\section{STYLING SAFE EDUCATION IN EXPERIMENTS}

Lu You, a poet of the Southern Song Dynasty, wrote in his teaching poem "reading on a winter night to show Zi Yu": it is easy to get on paper, and you must practice it. It is similar to safety education. The classroom safety education comprise the first section. However, the real practices should be more important and more efficacious for imparting the safety knowledge and experiences to the students. Thus, just as the training of professional knowledge in practice, the safety education is simultaneously conducted in the scientific experiments arranged for the students.

Shown in Figure 3 is some characterization experiments that are carried out in the first floor of the building of Materials Science and Engineering in University of Shanghai for Science and Technology. Besides the safety education from each instruments in included in the Room 107,105 and 103, the reasonable arrangement of them is also a safety education for the students, which the limited experimental space is also taken part into consideration. For example, OM often needs a very small space, and many samples can be firstly screened through OM and then they are observed using SEM for saving time and money. 
From a standpoint of safe operation, it is also a better organization that OM and SEM are placed into the same room due to the tight experimental space.

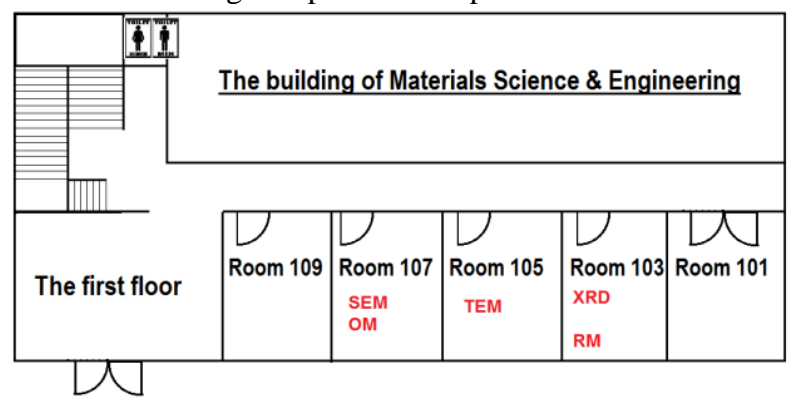

Figure 3. Some characterization experiments that are arranged in the first floor of the building of Materials Science and Engineering.

Shown in Figure 5 is some other characterization experiments that are carried out in the third floor of the building of Materials Science and Engineering. The UV-vis, DSC, and FTIR experiments are implemented in the same Room 310. To be straightforward, it is unsuitable that DSC is also arranged in this room due to high temperature is involved in this test. However, the arrangement of electrospinning in Room 304 is all right for preparing samples for all kinds of characterizations. Electrospinning is an electrohydrodynamic atomization methods, just as electrospraying [1-4]. It takes the advantages of the easy interactions between the working fluids with the electrostatic high voltage energy [5-9]. Thus, on one hand, several methods have been reported to how to save energy for production [10, 11]. On the other hand, the safety education become more and more important for the undergraduate and postgraduate students. Although this method is powerful in creating all types of nanostructures such as homogeneous [11-13], core-shell [14], Janus [15, $16]$, tri-layer core-shell $[17,18]$ and other complicated ones [19], thew first and foremost thing is to ensure the experiment in a controllable state and personal safety of all the students and experiment candidates.

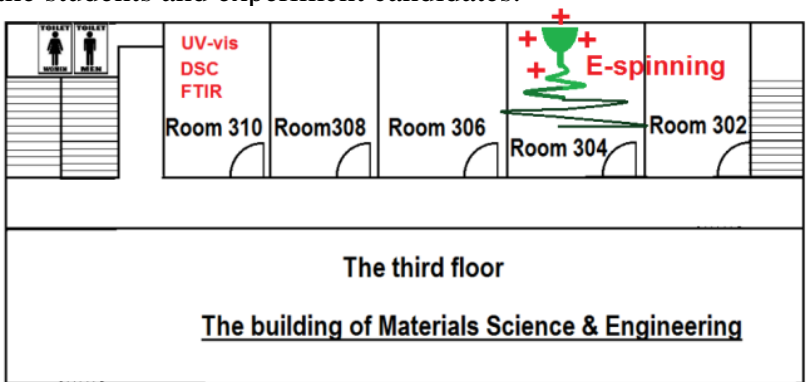

Figure 4. Some characterization experiments and the preparation of nanofibers that are arranged in the third floor of the building of Materials Science and Engineering.

\section{EXAMINATIONS ON SAFETY EDUCATION}

During the routine teaching life, the safety education in the classroom and also the experimental processes can impart the students the fundamental knowledge and skills about safety in scientific practices. However, some examinations for detecting the effects of safety education are needed, which should be also useful for evaluating the students' safety awareness.

In the final examination of "Advanced methods for materials characterization", a title about laboratory safe issues is given to the students to test their study effects during the classroom lessons and also the experiments.

The examination title (15 points) is shown as follows: This title has three sub-title, give your answers to each of them in detail.

(1) In the experimental lessons, we have conducted 8 experiments in different rooms, these experiments include OM, SEM, TEM, RM, FTIR, DSC, XRD, and UV-vis (has been done). Fill these experiments in the rooms, where they were carried out. (4 points)

(2) Give the full names of OM, SEM, TEM, RM, FTIR, $D S C, X R D$, and $U V$-vis. (4 points)

(3) Which one of those rooms is the most dangerous place, and point out the possible unsafe factors. (7 points)

The question 1 and 2 are objective questions, but question 3 is a subjective one. After analyses of the scores of 30 students, some issues deserve attention. Firstly, some students were blind at the Room number, which is shown by a lowest and an average value of 1.8 and 3.3 for Question 1, respectively. They entered the experimental rooms in a manner of following their classmates without clear sense of which room. This case reflects that the students still have no high safety awareness during their experimental processes. Secondly, Question 2 has a high average value of 3.8 , giving a hint that the classroom education and also the safety education are fine. Thirdly, there are very excellent answers on the subjective Question 3. A large number of the students clearly pointed out that the arrangement of UV-vis, DSC and FTIR was inappropriate, and Room 103 is the most dangerous place due to X-ray. Some classmates also pointed out that too many people are in an enclosed space is not good for defend COVID-2019. In general, the examinations about safety education have reached its purpose of melting the classroom and practice safety education in promoting the students' safety awareness.

\section{CONCLUSION}

In this paper, safety education associated with scientific practices in university is carefully discussed. Based on a professional course, i.e. "Advanced methods for materials characterization" and the spirit of "three-whole education", an integrated method for implementing the safety 
education is successfully demonstrated. In the classroom lessons, the students are taught about the fundamental knowledge and meanwhile the theoretical knowledge about safe analyses. Later, in the laboratory, the students are trained to carry out the experiments in a safe manner, paying attention to keeping all the possible harms from them. Finally, in the examination, the integrated manner of safety education is evaluated, which should be useful for improving the students' awareness on safe scientific practices.

\section{ACKNOWLEDGMENT}

The paper is financially supported by the projects of "Ideological and political teaching of graduate courses in Shanghai University of Technology", "Ideological and political research of SME-USST, and Shanghai Innovation Projects for College Students (Nos. SH2021259, SH2021257, and SH2021253).

\section{REFERENCES}

[1] Hou J, Yang Y, Yu DG, Chen Z, Wang K, Liu Y and Williams GR 2021. Multifunctional fabrics finished using electrosprayed hybrid Janus particles containing nanocatalysts. Chem. Eng. J. 411, 128474.

Doi:10.1016/j.cej.2021.128474

[2] Wang P, Wang M, Wan X, Zhou H, Zhang H and Yu DG 2020. Dual-stage release of ketoprofen from electrosprayed core-shell hybrid polyvinyl pyrrolidone/ethyl cellolose nanoparticles. Mater. Highlight. 1-2, 14-21. Doi:10.2991/mathi.k.200521.002

[3] Kang S, He Y, Yu DG, Li W and Wang K 2021. Drug-zein@lipid hybrid nanoparticles: Electrospraying preparation and drug extended release application.

Colloid. Surf. B 201, 111629.

Doi:10.1016/j.colsurfb.2021.111629

[4] Wang K, Wen HF, Yu DG, Yang YY and Zhang DF 2018. Electrosprayed hydrophilic nanocomposites coated with shellac for colon-specific delayed drug delivery. Mater. Des. 143, 248-255.

Doi:10.1016/j.matdes.2018.02.016

[5] Al-Jbour ND, Beg MD, Gimbun J and Alam AMM 2019. An overview of chitosan nanofibers and their applications in the drug delivery process. Curr. Drug Deliv. 16, 272-294.

Doi: $10.2174 / 1567201816666190123121425$

[6] Yu DG 2021. Preface-bettering drug delivery knowledge from pharmaceutical techniques and excipients. Curr. Drug Deliv. 18, 2-3. Doi:10.2174/156720181801201203091653

[7] Yang X, Chen S, Liu X, Yu M and Liu X 2019. Drug delivery based on nanotechnology for target bone disease. Curr. Drug Deliv. 16, 782-792.

Doi:10.2174/1567201816666190917123948

[8] Wang M, Li D, Li J, Li S, Chen Z, Yu DG, Liu Z and Guo JZ 2020. Electrospun Janus zein-PVP nanofibers provide a two-stage controlled release of poorly water-soluble drugs. Mater. Des. 196, 109075. Doi:10.1016/j.matdes.2020.109075

[9] Lv H, Yu DG, Wang M and Ning T 2021.

Nanofabrication of Janus fibers through side-by-side electrospinning - A mini review. Mater. Highlight. 2, 18-22. Doi:10.2991/mathi.k.210212.001

[10] Kang S, Hou S, Chen X, Yu DG, Wang L, Li X and Williams GR 2020. Energy-saving electrospinning with a concentric Teflon-core rod spinneret to create medicated nanofibers. Polymers 12, 2421.

Doi:10.3390/polym12102421

[11] Wang Y, Tian L, Zhu T, Mei J, Chen Z and Yu DG 2021. Electrospun aspirin/Eudragit/lipid hybrid nanofibers for colon-targeted delivery using an energysaving process. Chem. Res. Chinese Universities 37, 443-449. Doi:10.1007/s40242-021-1006-9

[12] Vlachou M, Kikionis S, Siamidi A, Tragou K, Kapoti S, Ioannou E, Roussis V and Tsotinis A 2019. Fabrication and characterization of electrospun nanofibers for the modified release of the chronobiotic hormone melatonin. Curr. Drug Deliv. 16, 79-85. Doi:10.2174/1567201815666180914095701

[13] Mofidfar M and Prausnitz MR 2019. Electrospun transdermal patch for contraceptive hormone delivery. Curr. Drug Deliv. 16, 577-583.

Doi:10.2174/1567201816666190308112010

[14] Ding Y, Dou C, Chang S, Xie Z, Yu DG, Liu Y and Shao J 2020. Core-shell Eudragit S100 nanofibers prepared via triaxial electrospinning to provide a colontargeted extended drug release. Polymers 12, 2034. Doi:10.3390/polym12092034

[15] Zheng X, Kang S, Wang K, Yang YY, Yu DG, Wan F, Williams GR and Annie Bligh S-W 2021. Combination of structure-performance and shapeperformance relationships for better biphasic release in electrospun Janus fibers. Int. J. Pharm. 596, 120203. Doi:10.1016/j.ijpharm.2021.120203 
[16] Li D, Wang M, Song WL; Yu DG and Annie-Bligh SW 2021. Electrospun Janus beads-on-a-string structures for different types of controlled release profiles of double drugs. Biomolecules 11, 635. Doi:10.3390/biom11050635

[17] Wang M, Yu DG, Li X and Williams GR 2020. The development and bio-applications of multifluid electrospinning. Mater. Highlight. 1-2, 1-13.

Doi:10.2991/mathi.k.200521.001
[18] Wang M, Hou J, Yu DG, Li S, Zhu J and Chen Z 2020. Electrospun tri-layer nanodepots for sustained release of acyclovir. J. Alloy. Compd. 846, 156471. Doi:10.1016/j.jallcom.2020.156471

[19] Aidana Y, Wang YB, Li J, Chang SY, Wang K and Yu DG 2021. Fast dissolution electrospun medicated nanofifibers for effective delivery of poorly water soluble drugs. Curr. Drug. Deliv. 18, 4-21. Doi:10.2174/1567201818666210215110359 